\title{
Application of Flipped Classroom in VB Program Design Experiment
}

\section{Teaching}

\author{
Jin Ling \\ Jiangxi University of Technology
}

Keywords: Flipped Classroom; VB program Design; Experiment Teaching

\begin{abstract}
Flipped classroom is a classroom in which knowledge instruction and internalization carried out in traditional classrooms are inverted, and a powerful means for promoting interaction between teachers and students and arousing students' interest. The VB program design experiment teaching, based on flipped classrooms, is mainly comprised of three parts: pre-class learning, exchange and cooperation in classrooms, and after-class reflection. Each part is provided with specific implementation plans and procedures, using the basic theory of flipped classroom to establish flipped experiment teaching environments and effectively solve the problems existing in the experiment teaching.
\end{abstract}

\section{Introduction of Flipped Classroom}

Flipped classroom, also called inverted classroom, is a new teaching method that students learn by themselves through the learning videos made by the teacher before class, while the classroom becomes a place where exchange and communication are made between teachers and students and among students and assignments. It is a new method for teaching and learning.

The teaching mode originates from America. In the spring of 2007, Jon Bergmann and Aaron Sams, chemical teachers in Woodland Park High School in Colorado, attempted to record the instruction process of presentation files by using screen recording software and upload ing the recorded videos onto the internet, in order to solve the problems that some students failed to come to class due to weather and to help them to learn the course out of class. The two teachers popularized the method and made students watch instruction videos out of class, while focusing on discussing assignments with students and providing assistance for those students with difficulties in experiments. For significant effect, the practices of the teachers drawn attention from their peers gradually until a "whirlwind" network teaching were started in Khan Academy in 2011, and from then on, flipped classroom had been familiarized by vast teachers, and had gained wide attention from educational circles across the world.

Since 2012, flipped classroom has become a hot subject studied in the field of education. Wall Street Journal, New York Times, etc. showed great concern about flipped classroom and reported it in large volumes, and the Globe and Mail also rated it as a significant technique reform affecting classroom teaching.

He Kekang and Li Jiahou, Chinese scholars and professors, have paid attention to flipped classroom for many times, and many teachers have been making constant explorations in their specific practices. Liu Xiaojing, an associate professor, applied the mode of flipped classroom into their data structure course teaching; and Teacher Zeng Mingxing also conducted flipped classroom 
reform and experiments in software development courses; however few teachers used the mode in VB program design course, especially in experimental courses. VB program design is a course with very strong practicality, so the research of flipped classroom in experimental courses has important academic value, which will provide experiment teaching with new methods and modes.

\section{Experiment Teaching Model Design of VB Program Design Based on Flipped Classroom}

Through learning of the VB program design course, it is hoped to cultivate students' program development and design abilities and computer thinking ability. A certain number of experimental operations can help students enhance the understanding of concepts and the command of knowledge, so the experimental courses of VB program design is vital. However, according to teaching experience, it has been found during experiment teaching that the follow faults:

(1) It is hard to complete teaching contents due to insufficient experimental course hours. For large-scale design and comprehensive experiments, students have to finish algorithm design, programming, debugging, tracing, running, etc. , so two classes are not enough obviously.

(2) The initiative of students cannot be aroused due to the experimental contents not updated with the time. The experiments of VB program design are basically the duplicates of some teaching cases, and part of the experimental contents even deviate from the times. These antiquated contents can greatly enhance the participation and initiative of students.

Necessity to apply flipped classroom to experiment teaching. Because of less experiment time and in order to finish learning tasks, students have not too much time to exchange with each other. This makes the students who can do an experiment busy with it and the other students who cannot do it idle, when they are doing the experiment. Therefore, it is hard to ensure the effect of the experiment. After flipped classroom, students first watch the operation steps and methods provided by the teacher out of class in advance, and then they will focus on the operation of the current experiment in the classroom, improving the efficiency and easing insufficient class hours. When meeting an experimental operation that cannot be understood, students can simulate the teacher while watching the teaching video, without turning to the teacher for help, and the teacher can save more time to provide individual assistance. Besides, the teacher also can record the latest teaching contents of program design into an operation video as a beneficial supplement to the textbook for after-class self-learning by students, thus improving their initiative. Therefore, these problems occurring during VB program experiment teaching can be effectively solved by using the flipped classroom teaching mode.

Experiment Teaching Model Design Based on Flipped Classroom. By using the basic theory of flipped classroom, the article establishes an experiment teaching mode based on flipped classroom and divides the flipped classroom into three phases: learning design before class, exchange in class, and reflection after class. The implementation process and plan in each phase is shown in the following figure:

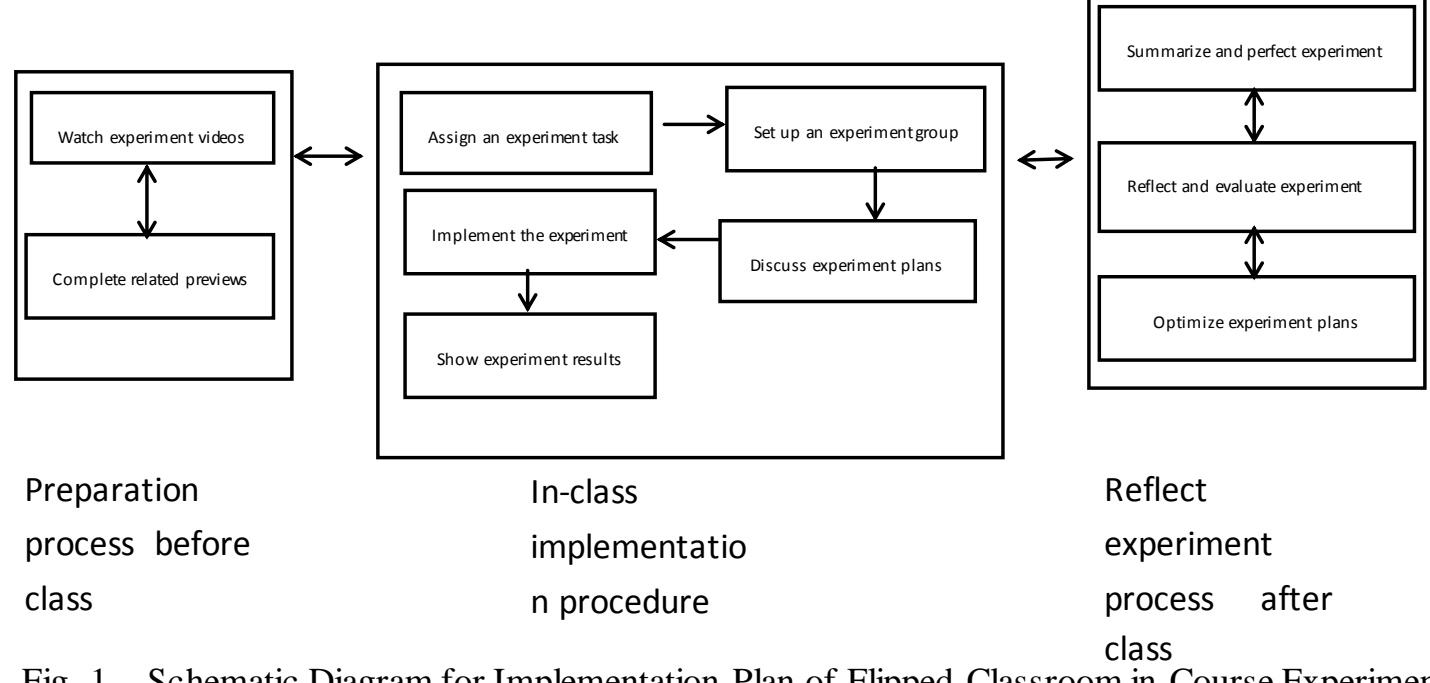

Fig. 1 Schematic Diagram for Implementation Plan of Flipped Classroom in Course Experiment Teaching 
Experime nt preparation phase before class. The main object in this phase: The teacher develops course resources and guides students to actively take part in learning the resources and completing related previews.

The teacher should, based on experimental contents, arrange related learning re sources (including micro lecture, operation video, electronic courseware, experimental operation procedures and codes, etc.) and make such resources into corresponding videos or files for use by different knowledge styles of students. At the same time, the teacher should provide the students with learning contents guide and appoint knowledge key points in advance, key operation steps of experiments, etc. on a learning network platform (such as QQ group, WeChat, related school websites), and make deep guide plans based on the feedback of guide and assignments so as to design the experimental contents and steps of next links for enhancing and deepening knowledge.

Through watching experiment videos, the students preview experiment teaching contents in advance and make experiment design on the foundation of understanding deeply basic theories, including experiment tasks such as algorithm description, flow chart design, etc. During the process, students can discuss and exchange what they have learned online or offline and can exchange with the teacher the problems they have meet in their previews.

Design of classroom communication activities. According to different experiment natures, the communication activities in a flipped classroom can be divided into two types: design experiment flipped teaching design and comprehensive experiment flipped teaching design.

The former requires students to grasp knowledge such as program design basics, three program structures and typical program algorithms via experiment processes. It is implemented through students' questions, communication between the teacher and students, and personalized classified guide by the teacher. Firstly, students put forward questions on experimental contents according to pre-class preview results and communicate with each other and answer such questions. For the common problems that cannot be solved, the teacher may solve them in class; for personalized problems, the teacher should provide one-to-one assistance.

The latter is to drill the ability of students to transfer knowledge. It is implemented in both methods: teacher guide, and exploration and study via coordination among students Firstly, the teacher should assign experiment tasks, and students are divided into different groups according to their interests and understanding, the scale of which is controlled within 6-8 students according to the number of one row of computers. And then experimental contents in each group is divided according to the difficulty and types of problems and completed by all members of each group. Finally the results are reported in class, and the reporter should explain in detail the solutions to problems and the implementation method and take the questions put forward by other teachers and students to promote students' better realization of knowledge internalization and absorption.

During this process, teacher should trace and provide guide. When finding a problem existing in the experiment conducted by students, the teacher should provide timely guidance so as to effectively control the progress of the experiment. When a student communicate with the teacher or other students, he/she may produce new inspirations, which can further perfect his/her experiment process. 
After-class reflection design. After class, students should show the experiment work done by their groups or individually. In this way, all members of each group taken part in the learning can share the result of their group. In the process, students can draw lessons from the results of other students and improve their experiment process or plan so as to make new improvements.

The teacher may further optimize the design plan for teaching resources according to experiment progress and results in order to lay a good foundation for subsequence flipping. The teacher also may collect developing resources related to experimental contents and upgrade task design, and the students with more learning capacity can challenge and upgrade tasks and realize enhancement and development of knowledge.

\section{Conclusions}

The application of flipped classroom in VB program design experimental courses is a beneficial attempt to teaching. The teacher is no longer the controller of class but a coordinator and guider; and the students are no longer passive receivers but the master of class. An unprecedented active status takes on in the process of learning.

The study of flipped classroom in China just starts, so the actual effect and application of flipped classroom in experimental course teaching in colleges and universities need further research by teachers and scholars. However, flipped classroom will certainly have a far-reaching influence on education reform with the development of education informatization.

Acknowledgment

This work was financially supported by the key subject building project (Computer science and technology) of Jiangxi University of Technology.

\section{References}

[1] Zeng Mingxing, Zhou Qingping, Cao Guomin, et al. , Study of Teaching Mode of Flipped Classroom for Software Development Courses [J], Laboratory Research and Exploration, 2014, 33(2): pp 203-209.

[2] Liu Rui, Wang Haiyan, Design and Practice of "Flipped Classroom" Teaching Mode based on vko.cn [J], Modern Educational Technology, 2014, 24(5): pp 26-31.

[3] Zhang Qiliang, Chen Yongsheng, Application Study of Flipped Classroom in Operating System Experiment Teaching [J], Experimental Technology and Management, 2014, (12): pp 173-176.

[4] Liu Xiaojing, Zhongqi, Zhang Qianping, Application Study of Flipped Classroom in "Data Structure" Course Teaching [J], China Educational Technology, 2014, (8): pp 105-110.

[5] Lin Qingsong, Experimental Course Design of "Modern Educational Technology" Based on Flipped Classroom [J], Laboratory Research and Exploration, 2014, 33(1): pp194-198 .

[6] Dong Liming, Jiao Baocong, Teaching Applied Mode Study Based on Flipped Classroom Idea [J], E-education Research, 2014.7: pp 108-114.

[7] Wu Shan, Liu Wenbin, Preliminary Exploration of Mathematics Teaching Design in Private Colleges and Universities, Chinese Journal of Education, 2014.08: pp 15-17.

[8] Zhang Jinlei, Wang Ying, Zhang Baohui. Introducing a new teaching model: Flipped 
classroom[J], Journal of Distance Education, 2012 (04) : pp 46-51.

[9] Gregory S. Mason, Teodora Rutar Shuman, Kathleen E. Cook. Comparing the Effectiveness of an Inverted Classroom to a Traditional Classroom in an Upper-Division Engineering Course[J]. IEEE Transactions on Education,2013(4): pp 430-435.

[10] Randall S. Davies, Douglas L. Dean, Nick Ball. Flipping the classroom and instructional technology integrationin a college-level information systems spreadsheet course[J]. Educational Technology Research andDevelopment,2013(4): pp 563-580. 